Special issue of the 2nd International Conference on Computational and Experimental Science and Engineering (ICCESEN 2015)

\title{
Optimal Design of Light Commercial Vehicle Headlamp for Pedestrian Protection
}

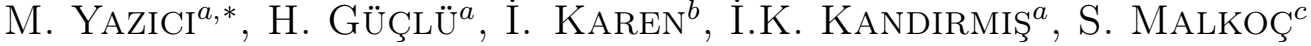 \\ AND Ö.F. BUYUKLUOĞLU ${ }^{b}$ \\ ${ }^{a}$ Dep. of Automotive Engineering, Faculty of Engineering, Uludag University, Bursa, Turkey \\ ${ }^{b}$ Dep. of Mechanical Engineering, Faculty of Engineering, Bursa Orhangazi University, Bursa, Turkey \\ ${ }^{c}$ Magneti Marelli MAKO Inc., Bursa, Turkey
}

\begin{abstract}
In this study, the headlamp of a light commercial vehicle was optimized in the way of pedestrian safety. This work aims to prevent harms to pedestrians in the urban crashes. Finite element analysis models of current headlamp and impactors representing pedestrian body forms were created. Static, modal and dynamic/explicit analyses were carried out by using existing and optimized headlamp models. Both models were in the simulations under the same boundary conditions. The results of two conditions were compared with each other. The results showed that connection regions of the headlamp have a major effect on pedestrian safety in pedestrian-vehicle collisions.
\end{abstract}

DOI: 10.12693/APhysPolA.130.262

PACS/topics: 46.40.-f, 02.70.Bf

\section{Introduction}

Nowadays, pedestrian protection is one of the most important criteria for the design and manufacturing of vehicles. In Europe, 21\% [1] and in Turkey 24\% [2] of urban traffic accidents fatalities are caused by pedestrianvehicle collision. Using the full-scale dummy models in the pedestrian-vehicle crash test procedure are high-cost when to compare with utilizing the impactors. Also using the impactors instead of full-scale dummy models reduce the test procedure time and simulations time. Working Group 17 of the European Enhanced Vehicle Safety Committee (EEVC/WG17) proposed three test methods for determining the behaviour of pedestrian-vehicle collision and impactors instead of pedestrian body parts around crash regions [3].

In literature, a number of studies have been performed to development and validation of the impactors and determine the optimum front-end design for pedestrian protection. Teng and Nguyen modeled the impactors for crash analysis and compared the results according to EEVC/WG17 regulations [4]. Khoo and Tarlochan validated lower legform [5]. Samaka and Tarlochan modelled and validated the adult headform to evaluate the car hood design [6]. Abvabi et al. performed a finite element simulation of the lower legform [7]. Xiaojiang et al. optimized the vehicle's front-end structure using the lower legform [8].

In this study, a commercial vehicle headlamp was optimized according to pedestrian safety regulations on pedestrian impact as well as static loading and natural vibrations by using finite element simulations. Child

\footnotetext{
* corresponding author; e-mail: myazici@uludag.edu.tr
}

head impact case was selected as a pedestrian crash case. Three areas of child head collision are taken into account [9]. In the simulations, the collision accepted through in the upper area of the headlamp front lens was used. Headlamp housing and lens materials were selected as talc added polypropylene material (PPTD40) and polycarbonate (PC), respectively. Totally, 47 different parts with 15 different materials exist in the manufacturing of the headlamp. The child headform and headlamp were modeled for static, modal and non-linear dynamic/explicit finite element analysis. According to results of the crash analyses, the housing model was optimised on child head impact as well as natural vibration modes and static loading cases. Finally, improved model was simulated for all loading conditions.

\section{Materials and methods}

In this study, three different analyses: static, modal, and the non-linear dynamic/explicit impact analysis were conducted for each condition. Four different finite element models were executed in the analyses. The software used in the simulations was Abaqus/Standard and Abaqus/Explicit. Material constants of low and high strain rate were determined using the uniaxial tensile machine and Split-Hopkinson Pressure Bar equipment for the dynamic analysis.

\subsection{Experimental characterization of the materials properties}

High strain rate material properties of PPTD40 $(60 \% \mathrm{PP}$ and $40 \%$ talc) were obtained from SplitHopkinson Pressure Bar tests. Maraging steel of $1220 \mathrm{~mm}$ length and $12.7 \mathrm{~mm}$ diameter bars were selected for the incident and transmitted bars. A copper pulse shaper was used to improve the force equilibrium conditions at the specimen-bar interfaces. The low strain rate 
properties were determined using uniaxial tensile test. Specimens of the PPTD40, which using determined low strain rate material constants, was fabricated utilizing plastic injection mold. The tensile specimens were produced in compliance with ASTM 638 standards. The results were given in Fig. 1.
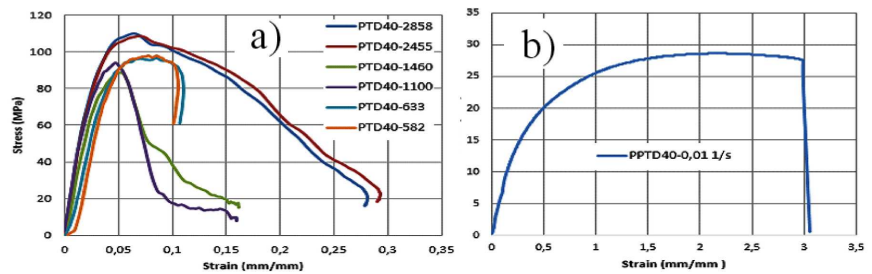

Fig. 1. Stress-strain curves for PPTD40 at (a) high and (b) low strain rates.

\subsection{Finite element simulations}

Finite element model of headlamp was created for static, modal, and crash analysis by using existing headlamp model and improved headlamp model for pedestrian safety. Car body connection regions of both models can be seen in Fig. 2. Elastic material properties, which are given in Table I, were defined for each headlamp components to execute the static and modal analysis. Static analyses were performed with gravity loading boundary condition. In modal analyses, first mode shapes were calculated. Linear contacts were used in the static and modal analyses. All components were composed of solid elements.

TABLE I

Material properties of headlamp components.

\begin{tabular}{c|c|c|c|c}
\hline \hline Materials & $\begin{array}{c}\text { Young } \\
\text { modulus } \\
{[\mathrm{MPa}]}\end{array}$ & $\begin{array}{c}\text { Density } \\
{\left[\mathrm{g} / \mathrm{cm}^{3}\right]}\end{array}$ & $\begin{array}{c}\text { Poisson } \\
\text { ratio }\end{array}$ & $\begin{array}{c}\text { Yield } \\
\text { strength } \\
{[\mathrm{MPa}]}\end{array}$ \\
\hline PC & 2350 & 1.2 & 0.38 & 63 \\
PBT & 2400 & 1.3 & 0.28 & 60 \\
PPTD40 & 3500 & 1.2 & 0.38 & 32 \\
BMC & 13000 & 1.9 & 0.35 & 77 \\
POM & 3000 & 1.42 & 0.35 & 72
\end{tabular}

The headlamp model consists of 627,047 nodes, 2,328,007 linear tetrahedral elements, and 2924 linear hexahedral elements. Total mass is $2.94 \mathrm{~kg}$ for the headlamp model. In the pedestrian-vehicle impact cases, four different bodyforms were proposed in the crash analyses according to EEVC/WG17 standards (Fig. 3). The child headform was selected in this study. Then the child headform and headlamp finite element models were created. Child headform impactor is a sphere made of aluminum covered with an $11 \pm 0.5 \mathrm{~mm}$ vinyl skin. The vinyl skin was modelled with viscoelastic material and aluminum core as an elastic-plastic material. The child headform finite element model consisted of 23,946 nodes and 110,589 linear tetrahedral elements. High strain rate material

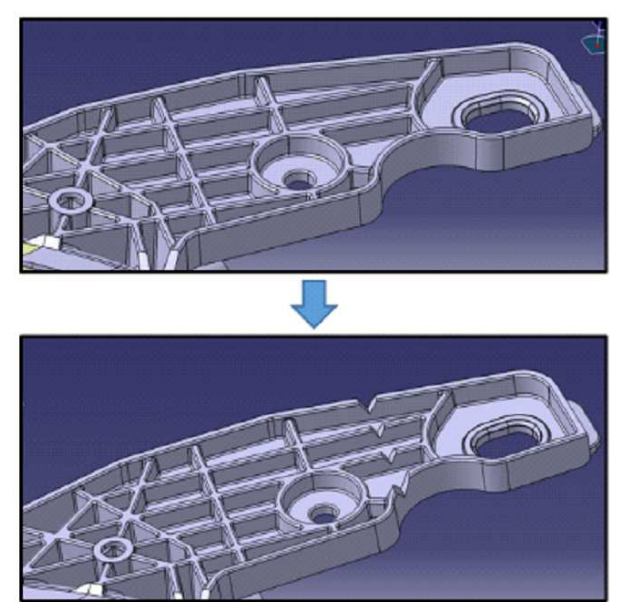

Fig. 2. Model improvement for pedestrian crash impact.

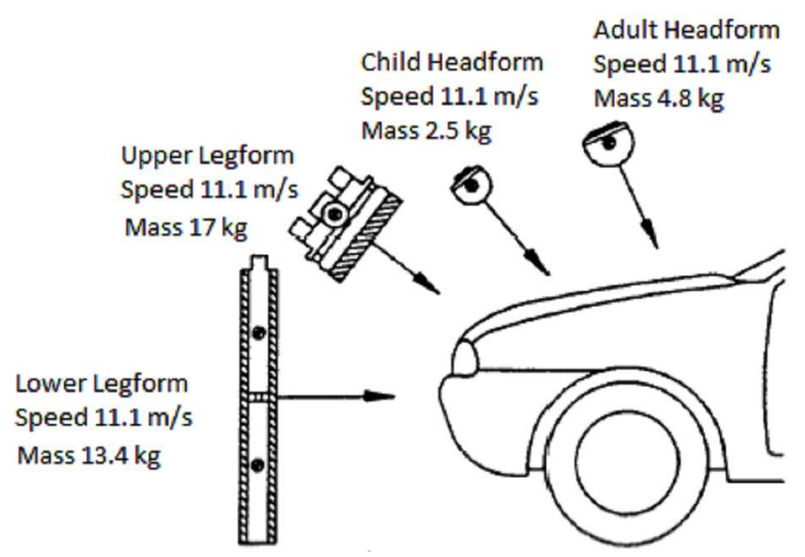

Fig. 3. Pedestrian protection test methods [3].

constants of PPTD40 that using in housing was taken from experimental results. High strain rate properties of PC that are using the lens were taken from literature [10]. The finite element model of crash analyses consisted 531,747 nodes and 1,851,841 linear tetrahedral elements. Child headform was impacted with the speed of $11.1 \mathrm{~m} / \mathrm{s}$ according to EEVC regulations to the headlamp upper top surface with a 55 angle from ground plane [3]. In the crash analysis, the model simplified due to reducing solution time, and only the lens and housing of headlamp were selected. Figure 4 illustrates finite

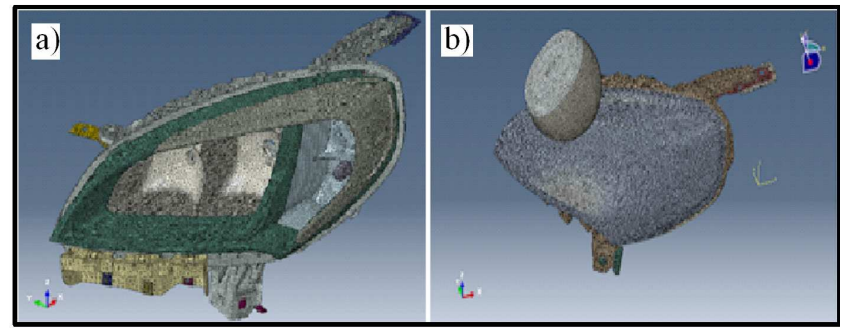

Fig. 4. FEM models: (a) static and modal, (b) nonlinear dynamic/explicit analysis. 
element model (FEM) of static, modal, and non-linear dynamic/explicit analysis.

\section{Results and discussions}

The results of the static and modal analyses were shown in Fig. 5. In static analyses, obtained maximum equivalent stress $(2.306 \mathrm{MPa})$ was much less than the yield stress of the PPTD40 headlamp housing materials (32 $\mathrm{MPa})$. In modal analysis obtained first mode frequency was $73 \mathrm{~Hz}$. According to OEM's requirements first mode of headlamp must be higher than $42 \mathrm{~Hz}$. The static and modal finite element analysis (FEA) results showed that the existing housing model is safe for gravity loading and natural mode shape.

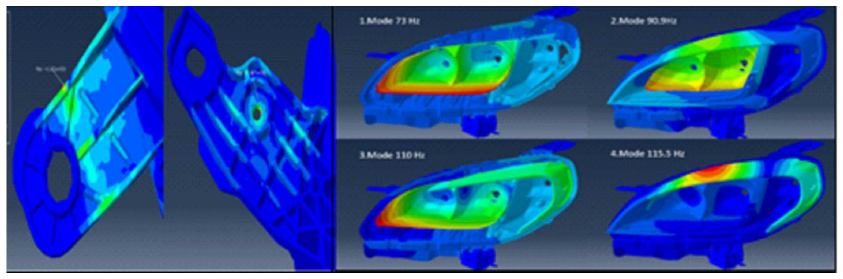

Fig. 5. Results of the static and modal analysis.
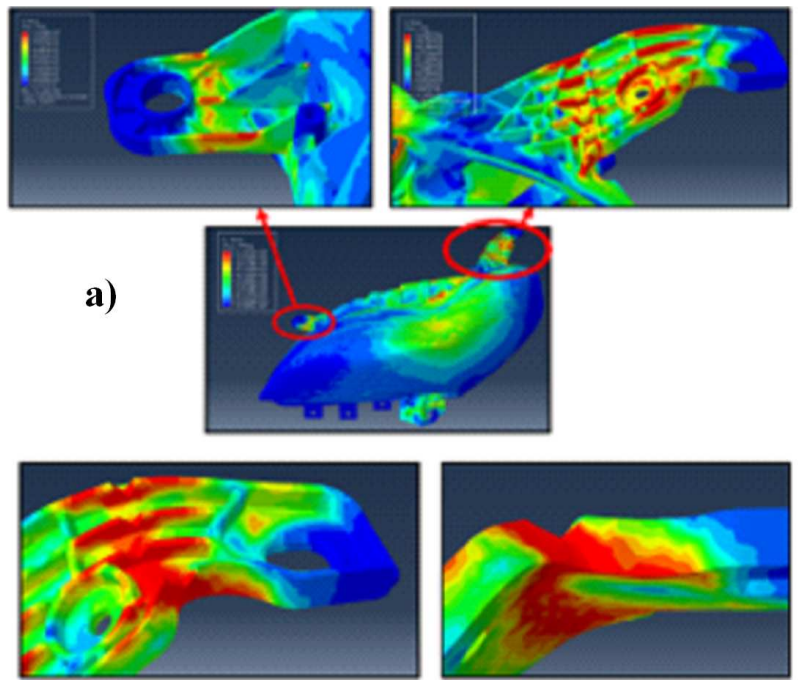

b)

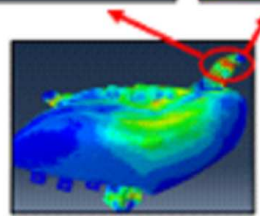

Fig. 6. Results of the crash analyses: (a) existing headlamp housing model, (b) improved headlamp housing model.

The headlamp housing connection region locally yielded in the pedestrian-child headform impact simulation (Fig. 6a). However, it is not enough to totally fracture of the headlamp connection region and does not let the headlamp free to slide inside the carbody. Figure $6 \mathrm{~b}$ shows the improved model simulation results subjected to child head impact load. It can be seen that the yielded region dissipated through the whole section around the notched region. That means this connection region will be broken when the child head impacts the headlamp. Acceleration values of child head were also decreased around $6 g$ by improving the headlamp housing model. These results fulfill the pedestrian protection requirements according to child head impact. To optimize the results, the improved model was checked again with static and modal simulations.

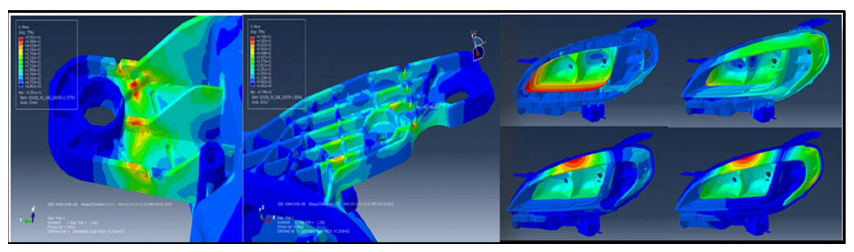

Fig. 7. Static and modal simulations of the improved headlamp for model validations.

Figure 7 illustrates static and modal simulation of the improved model of headlamp. The static condition maximum equivalent stress was $1.77 \mathrm{MPa}$, and first frequency mode was around $75 \mathrm{~Hz}$. Both cases were in the safe regions.

\section{Conclusions}

In this study, a new headlamp housing design was performed in the term of pedestrian protection. The existing model of headlamp was examined for static, modal, and child head impact conditions. All static analysis results were obtained in the safe zone. The first mode of the headlamp must be greater than $42 \mathrm{~Hz}$ according to OEM's data. After crash analysis carried out in compliance with the EEVC/WG17 regulations critical zones of the housing model were determined. New headlamp housing model was created by weakening in the critical zones of the existing model to reduce stresses around headlamp housing connection regions in a crash event. Then notched model was checked for static and modal condition. Exact failure occurred in the critical zones of housing according to results of the non-linear dynamic/explicit analysis with modified model of housing.

The simulation results showed that the proposed optimal model of the headlamp is a pedestrian-friendly model on childhead-headlamp impact case which is one of the most often occurring pedestrian-vehicle collision case.

\section{Acknowledgments}

The authors would like to thank Dr. Arun Shukla for providing an opportunity to study in the DynamicPhotomechanic Laboratory (DPML), The University of Rhode Island, USA. The authors also would like to thank Mr. Craig Tilton, and Mr. Prathmesh Parrikar for 
their help to perform SHPB experiments from DPML. The authors also acknowledge the financial support of this study provided by Ministry of Science, Industry and Technology of Republic of Turkey, under Project Number: 0227.STZ.2013-1.

\section{References}

[1] Transport, Road Safety, Users, Pedestrians, European Community, Last update: October 22, 2014.

[2] The Responsibility and Causes of Traffic Accidents, Summary of Information, General Directorate of Highways and Road Network, 2014, (in Turkish).

[3] EEVC Working Group 17 Report, Improved Test Methods to Evaluate Pedestrian Protection Afforded by Passenger Cars, December 1998 with September 2002 updates.

[4] T.L. Teng, T.H. Nguyen, J. Mech. Sci. Technol. 22, 1660 (2008).
[5] Y.C. Khoo, F. Tarlachan, Int. J. Res. Eng. Technol. 2, 137 (2013)

[6] H.M. Samaka, F. Tarlachan, Int. J. Sci. Technol. Res. 2, 44 (2013).

[7] A. Abvabi, A. Nasr, A. Noorpoor, M.S. Kiasat, Safety Sci. 48, 660 (2010).

[8] L. Xiaojiang, G. Xianguang, H. Liangguo, Z. Dayong, L. Weignuo, Thin-Walled Struct. 94, 500 (2015).

[9] B. Wördenweber, J. Wallaschek, P. Boyce, D.D. Hoffman, Automotive Lighting and Human Vision, Springer-Verlag, Berlin 2007.

[10] A. Dwivedi, J. Bradley, D. Casem, February 2012 Mechanical Response of Polycarbonate with Strength Model Fits, U.S. Army Research Laboratory ATTN: RDRL-WMP-B Aberdeen Proving Ground, MD 21005-5069, ARL-TR-5899, Final Report. 